\title{
Small for dates babies: are they really a problem?
}

\author{
R A K JONES AND N R C ROBERTON
}

The Neonatal Unit, The Rosie Maternity Hospital, Cambridge

SUMmaRY One hundred and sixty four infants $<5$ th centile for gestation specific birth weight were born at gestations $\geqslant 37$ weeks in the Cambridge Maternity Hospital in 1982. Of these, 60 were $<2 \cdot 3$ rd centile - that is, $>2$ standard deviations below mean birth weight. Serious disease was rare: only six $(4 \%)$ had recognisable malformations. There was only one neonatal death, a baby $<2 \cdot 3$ rd centile with the Neu-Laxova syndrome. Nine $(5 \%)$ became hypoglycaemic but with no serious symptoms: one of these was already on the neonatal unit with respiratory distress syndrome and was given intravenous dextrose, and the remaining eight all responded to milk feeds. Only 13 out of the 164 patients $(8 \%)$ were admitted to the neonatal unit, eight of the 12 survivors for 48 hours or less.

Small for dates babies of 37 weeks' gestation or more pose few neonatal problems and can be safely cared for on a postnatal ward.

In the past small for dates babies have caused appreciable concern to their medical attendants. According to the 1958 perinatal mortality survey infants with birth weight $\leqslant 2500 \mathrm{~g}$ born after full duration or prolonged pregnancies had a mortality eight times higher than those weighing $>2500 \mathrm{~g}$. ${ }^{1}$ The danger of symptomatic hypoglycaemia was first recognised in $1959 .^{2}$ Many other neonatal complications, such as birth asphyxia, hypothermia, sepsis, polycythaemia, pulmonary haemorrhage, and an increased risk of congenital abnormality, have been reported in small for dates infants. ${ }^{3}$ Ounsted et al found that only $35 \%$ of a cohort of infants more than 2 standard deviations below the mean birth weight for gestation had an uncomplicated neonatal course, and their neonatal mortality was 63 per 1000 live births. ${ }^{4}$ In recent years, however, our impression has been that with improved standards of obstetrics and routine neonatal care, small for dates infants other than those with complications attributable to short gestation have caused few problems.

\section{Patients and methods}

It is our policy to admit to the neonatal unit only babies who have symptoms or who weigh $<1800 \mathrm{~g}$; asymptomatic babies above this weight go to the postnatal wards irrespective of gestation or whether they are small for dates or not.

Since 1975 the routine on the postnatal wards in the Cambridge Maternity Hospital has been to record Dextrostix (Ames, United Kingdom) routinely at $2,6,12,24,36$, and 48 hours of age in all babies below the $2 \cdot 3$ rd centile. Dextrostix are performed in bigger infants at the discretion of the nursing or medical staff. As well as having these Dextrostix measurements the babies receive $60 \mathrm{ml} / \mathrm{kg}$ of formula on day 1 and $90 \mathrm{ml} / \mathrm{kg}$ on day 2 , plus whatever they receive from the breast. ${ }^{5}$ In this study we have reviewed all 164 infants born in 1982 at Cambridge Maternity Hospital at gestations of 37 or more weeks (259 days or more) whose birth weights were below the fifth centile of Tanner and Thomson. ${ }^{6}$ These infants were termed 'small for dates. The mothers' and infants' notes were scrutinised for the presence of an antenatal diagnosis of poor growth, intrapartum asphyxia, intubation at birth, hypothermia $\left(<36^{\circ} \mathrm{C}\right)$, hypoglycaemia (glucose concentration $<1.4 \mathrm{mmol} / 1(25 \mathrm{mg} / 100 \mathrm{ml}$ on Dextrostix)), need for admission to the neonatal unit, and any neonatal illness.

For analysis, infants were divided into those above or below the $2 \cdot 3$ rd centile of Milner and Richards ${ }^{7}$ (equivalent to 2 SD below the mean birth weight for gestation). The $\chi^{2}$ test was used for comparing frequency distributions using Yates's correction for small numbers.

To extend our assessment of the safety of our practice we reviewed our records to find all those infants admitted to our neonatal unit with symptomatic hypoglycaemia during the six year period 1977-82, during which our postnatal ward routine was that described above. 


\section{Results}

1982 data. Intrauterine growth retardation was predicted in only $30 \%$ of singleton infants $<5$ th centile, rising to $44 \%$ of those $<2 \cdot 3$ rd centile. No baby, however, was born severely asphyxiated, and of the 15 who needed intermittent positive pressure ventilation in the labour ward all were in good condition and breathing spontaneously by 10 minutes of age. One of these 15 infants, weighing $1910 \mathrm{~g}$ and born at 37 weeks' gestation, was observed on the neonatal unit for 24 hours. Of eight stillbirths in 1982 more than 37 weeks' gestation, there were two with malformations (Potter's syndrome and isolated hydrocephalus), both of whom were of normal birth weight. The only small for dates stillbirth had been diagnosed antenatally as growth retarded, and although the mother was given a 'kick' chart and instructions, she failed to contact the hospital when fetal movements fell into the danger zone.

The neonatal problems are summarised in Table 1. Thirteen infants $(8 \%)$ were admitted to the neonatal unit for the reasons shown in Table 2, and

Table 1 Mortality and gross morbidity in 164 infants born in 1982 at Cambridge Maternity Hospital at gestations $\geqslant 37$ weeks with birth weights below the 5th centile. Numbers in brackets are percentages

\begin{tabular}{lccc}
\hline & \multicolumn{2}{l}{ Birthweight centile } & \multirow{2}{*}{ Total } \\
\cline { 2 - 3 } & $2 \cdot 3 r d-5 t h$ & $<2 \cdot 3 r d$ & \\
\hline Total live births & 104 & 60 & 164 \\
Twins & 15 & 6 & 21 \\
Malformations & 4 & 2 & 6 \\
Admitted to neonatal unit & $6(6)$ & $7(12)$ & $13(8)$ \\
Hypothermia $<36^{\circ} \mathrm{C}$ & $16(15)$ & $21(35)$ & $37(27)$ \\
Hypoglycaemia $<1 \cdot 4$ mmol/1 & $3(3)$ & $6(10)$ & $9(5)$ \\
Neonatal deaths & 0 & $1^{*}$ & $1 \dagger$ \\
\hline
\end{tabular}

*Neu-Laxova syndrome.

$+6 / 1000$ live births.

Table 2 Reasons for admission to neonatal unit and duration of stay in infants $\geqslant 37$ weeks' gestation $(n=164)$

\begin{tabular}{lcc}
\hline Diagnosis & $\begin{array}{l}\text { No of } \\
\text { infants }\end{array}$ & $\begin{array}{l}\text { Duration of stay } \\
(d=\text { days, h=hours })\end{array}$ \\
\hline $\begin{array}{l}\text { Birth weight }<1800 \mathrm{~g} \\
\text { Major malformation }\end{array}$ & 2 & $\begin{array}{l}4 \mathrm{~h}, 2 \mathrm{~d} \\
\text { One died, one sent to } \\
\text { another hospital }\end{array}$ \\
$\begin{array}{l}\text { Respiratory distress syndrome } \\
\text { Group B streptococcal sepsis }\end{array}$ & 1 & $\begin{array}{l}12 \mathrm{~d} \\
\text { 6d }\end{array}$ \\
$\begin{array}{l}\text { Meconium aspiration } \\
\text { Hypothermia }\end{array}$ & 2 & $2 \mathrm{~d}, 4 \mathrm{~d}$ \\
Birth asphyxia & 2 & $1 \mathrm{~d}, 2 \mathrm{~d}$ \\
\hline Total admissions & 2 & $12 \mathrm{~h}, 24 \mathrm{~h}$ \\
\hline
\end{tabular}

all of them were admitted from the labour ward immediately after delivery. Of the 11 babies who were not malformed who were initially admitted to the unit, eight had been discharged to the postnatal ward by 48 hours. Six infants $(4 \%)$ had a malformation recognised in the neonatal period (ventricular septal defect, Neu-Laxova syndrome, WerdnigHoffman disease, multicystic kidney, imperforate anus, and agenesis of the pinna), but only two of these, the baby with an imperforate anus and the case of Neu-Laxova syndrome, were admitted to the unit.

Hypothermia. As shown in Table 1, 37 of the 164 infants $(23 \%)$ had recorded temperatures below $36^{\circ} \mathrm{C}$. The incidence of this problem rose to 21 of 60 infants $(35 \%)$ below the $2 \cdot 3$ rd centile. This may be an underestimate of the incidence of hypothermia as $42 \%$ had no temperature recorded in their notes. Only six $(4 \%)$, however, had temperatures below $35^{\circ} \mathrm{C}$, the lowest being $34^{\circ} \mathrm{C}$. The lowest temperatures were virtually always those recorded in the first few hours of life while the infant was on the labour ward or shortly after admission with his mother to a postnatal ward. The temperatures all rose steadily thereafter, and no symptoms attributable to cold were seen. Two infants were admitted to the neonatal unit, however, because of their low temperature (Table 2).

Hypoglycaemia. Measurements were available in only $72 \%$ of infants $<5$ th centile but were recorded in $88 \%$ of those below the 2.3 rd centile. Concentrations of glucose below $1.4 \mathrm{mmol} / \mathrm{l}(25 \mathrm{mg} \%)$ were found in only nine infants, three of the 104 infants (3\%) with birth weights between the $2 \cdot 3 \mathrm{rd}$ and 5 th centile, and six of the $60(10 \%)$ below the $2 \cdot 3$ rd centile. The three infants with birth weights between the $2 \cdot 3$ rd and 5 th centiles were all on the postnatal ward, and their blood glucose concentration increased and remained normal after an extra milk feed. Of the six infants $<2 \cdot 3$ rd centile, there were five on the postnatal ward whose blood glucose concentrations rose with an extra feed. The sixth, already on the neonatal unit with transient tachypnoea of the newborn, was started on intravenous dextrose. Of these nine babies, eight were asymptomatic, and one was described as jittery. Thus no infant had serious symptoms from hypoglycaemia, and no infant was admitted to the neonatal unit solely for correction of hypoglycaemia.

1977-82 data. Out of nearly 23000 infants born in the Cambridge Maternity Hospital at 37 weeks' gestation or greater, there were 10 infants with symptomatic hypoglycaemia. Of these, three had 
fits, two had mild respiratory illness and were found coincidentally to have a blood glucose concentration $<1.1 \mathrm{mmol} / \mathrm{l}$, and the other five were just jittery. Only two, both of whom were jittery, were small for dates, and only one of these required intravenous dextrose to keep his glucose concentration $>1 \cdot 1$ $\mathrm{mmol} / \mathrm{l}$. Both have developed normally. The three

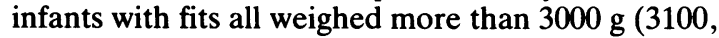
3300 , and $3400 \mathrm{~g}$ ), and apart from poor feeding no cause was ever found for their hypoglycaemia.

\section{Discussion}

Neonatal mortality in this study of 164 term, small for dates infants was limited to a single grossly malformed infant, and neonatal morbidity from acquired illness was uncommon and transient. If hypothermia is considered as being only below $35^{\circ} \mathrm{C}$ and birth asphyxia as only intermittent positive pressure ventilation beyond five minutes then the total morbidity was 31 of 164 infants $(19 \%)$, comprising six malformations, seven cases of birth asphyxia (one also of hypothermia), nine cases of hypoglycaemia (one each also of hypothermia and transient tachypnoea), four cases of isolated hypothermia, and five other admissions to the special care baby unit (three with respiratory symptoms and two solely for low birth weight). This is considerably less than has been reported in other series. This low incidence of complications was not due to growth retarded fetuses dying in utero. Despite the fact that most growth retarded infants were not recognised antenatally, the overall improvements in the general standard of intrapartum care and neonatal resuscitation in the last two decades must have contributed to the low incidence of complications such as hypoxic ischaemic encephalopathy, meconium aspiration, infection, and massive pulmonary haemorrhage, which traditionally are supposed to occur in growth retarded infants.

Small babies with a large surface area to body weight ratio are prone to hypothermia. The body temperature of too many babies in this study fell below $36^{\circ} \mathrm{C}$, usually while the infant was still on the labour ward. Improved labour ward procedures as a result of this study and a move to a new, better designed hospital have resulted in this problem virtually disappearing.

There remains a major anxiety in the minds of most paediatricians about hypoglycaemia in small for dates infants. This anxiety was created by the much cited studies of Neligan ${ }^{8}$ and Lubchenko and Bard, ${ }^{9}$ who reported an incidence of hypoglycaemia (presumed asymptomatic) of over $20 \%$ in growth retarded infants, and by studies such as those of Anderson et al, ${ }^{10}$ Cornblath et al,${ }^{2}$ Koivisto et al, ${ }^{11}$ and Pildes et al, ${ }^{12}$ reporting a high incidence of severe sequelae and neuropathological changes in infants who, as neonates, had symptoms attributed to hypoglycaemia.

It has to be emphasised, however, that most of these studies were from an era when neither early feeding of small for dates infants was pursued with the enthusiasm that was fostered by the studies of Smallpiece and Davies ${ }^{13}$ nor monitoring for asymptomatic hypoglycaemia in small for dates infants by Dextrostix was routine. In 1982 we reported a very low incidence $(5 / 167(3 \%))$ of asymptomatic hypoglycaemia using the above protocol in infants with a birth weight of $1800-2500 \mathrm{~g}$ (about half of whom were small for dates) nursed on a postnatal ward. ${ }^{14}$ A similarly low incidence of hypoglycaemia in adequately fed small for dates infants was reported by Walther and Ramaekers. ${ }^{15}$

This present study, provoked, in part, by the persisting controversy over our 1982 data that adequately fed and monitored small for dates babies could be safely cared for on a postnatal ward, confirms that even asymptomatic hypoglycaemia is rare $(9 / 164(5 \%))$ in small for dates infants. Those who are asymptomatic and with their mothers on a postnatal ward respond promptly to an extra feed. No small for dates infant in this study or that of Whitby et $a l^{14}$ developed symptomatic hypoglycaemia.

As it is uncertain whether jitteryness is a specific feature of neuroglycopenia or whether it is caused by 'smallness-for-dates' itself, we failed to diagnose hypoglycaemia before symptoms (fits) occurred in only three infants in the six year period 1977-82. None of them was below even the 10th birthweight centile for gestation, and none would, therefore, have been included in any currently recommended screening programme for detecting hypoglycaemia in small for dates infants.

Whether we missed any cases of asymptomatic hypoglycaemia in the period 1977-82 remains speculative. As there is no evidence that asymptomatic hypoglycaemia is associated with any long term sequelae ${ }^{3}$ we believe that detecting a biochemical abnormality of no clinical importancethat is, transient self correcting asymptomatic hypoglycaemia-serves no purpose. Furthermore, the data show that no small for dates infant with asymptomatic hypoglycaemia can have subsequently developed symptomatic hypoglycaemia (fits) in this six year period.

In the 1977-82 data only one infant was found with a weight between the $2 \cdot 3 \mathrm{rd}$ and 5 th centile who became hypoglycaemic and who required any treatment other than an extra feed to maintain a normal blood glucose concentration. As this baby 
was detected on clinical grounds, and as the blood glucose concentration in all the other infants in this birthweight band who developed asymptomatic hypoglycaemia rose to normal after a feed, we see no point in routinely screening any small for dates infants $>2 \cdot 3$ rd centile for birth weight for hypoglycaemia. Infants above this centile, however, irrespective of how far they are above this centile, who look wasted and malnourished, feed poorly, or develop appropriate symptoms, such as apnoea, pronounced jitteryness, and fits, should have their blood glucose concentration measured promptly.

\section{References}

${ }^{1}$ Butler NR, Bonham DG. Perinatal mortality. Edinburgh; E and S Livingstone, 1963.

2 Cornblath M, Odell GB, Levin EY. Symptomatic neonatal hypoglycemia associated with toxemia of pregnancy. $J$ Pediatr 1959;55:545-62.

3 Jones RAK, Roberton NRC. Problems of the small-for-dates baby. In: Howie PW, Patel NB, eds. The small baby. Clin Obstet Gynecol 1984;11:499-524.

4 Ounsted M, Moar V, Scott WA. Perinatal morbidity and mortality in small-for-dates babies: the relative importance of some maternal factors. Early Hum Dev 1981;5:367-75.

5 Roberton NRC. A manual of neonatal intensive care. London: Edward Arnold, 1986:151.

6 Tanner JM, Thomson AM. Standards for birthweight at gestation periods from 32-42 weeks, allowing for maternal weight and height. Arch Dis Child 1970;45:566-9.
${ }^{7}$ Milner RDG, Richards B. An analysis of birthweight by gestational age of infants born in England and Wales 1967-1971. Journal of Obstetrics and Gynaecology of the British Commonwealth 1974;81:956-67.

${ }^{8}$ Neligan GA, Robson E, Watson J. Hypoglycaemia in the newborn: a sequel of intrauterine malnutrition. Lancet $1963 ; \mathrm{i}: 1281-4$.

9 Lubchenko LO, Bard H. Incidence of hypoglycemia in newborn infants classified by birthweight and gestational age. Pediatrics 1971;47:831-8.

10 Anderson JM, Milner RDG, Strich SJ. Effects of neonatal hypoglycaemia on the nervous system: a pathological study. J Neurol Neurosurg Psychiatry 1967;30:295-310.

${ }^{11}$ Koivisto M, Blanco-Sequeiros M, Krause U. Neonatal symptomatic and asymptomatic hypoglycaemia: a follow-up study of 151 children. Dev Med Child Neurol 1972;14:603-14.

12 Pildes RS, Cornblath M, Warren I, et al. A prospective controlled study of neonatal hypoglycemia. Pediatrics 1974;54:5-14.

${ }^{13}$ Smallpiece V, Davies PA. Immediate feeding of premature infants with undiluted breast milk. Lancet 1964;ii:1349-52.

14 Whitby C, De Cates CR, Roberton NRC. Infants weighing $1.8-2.5 \mathrm{~kg}$ : should they be cared for in neonatal units or postnatal wards? Lancet 1982;i:322-5.

15 Walther FJ, Ramaekers LHJ. Neonatal morbidity of SGA infants in relation to their nutritional status at birth. Acta Paediatr Scand 1982;71:437-40.

Correspondence to Dr N R C Roberton, Department of Paediatrics, Addenbrooke's Hospital, Hills Road, Cambridge CB2 2QQ, England.

Received 25 March 1986 